\title{
Às cores fotográficas e a William Eggleston, breve reverência
}

\section{Wanderley Anchieta}

Mestrando do PPGCOM da Universidade Federal Fluminense, na linha de Tecnologias e Estéticas da Comunicação, sob a orientação do professor Benjamim Picado.

E-mail: wya@outlook.com
Resumo: $O$ trabalho versará sobre o ocaso que se instalou entre os críticos da fotografia de arte acerca da instalação das obras coloridas de William Eggleston em 1976, no MoMA de Nova lorque. Se as cores fotográficas - como se evidencia por ampla documentação histórica apurada pelo casal Henisch, por exemplo sempre foram ensejadas, por que Eggleston foi achincalhado com tanta veemência? Partindo da heurística da teoria da atenção estética, este trabalho procura explicar como o ato de Eggleston lançou ao primeiro plano da atenção (logo da discussão e apreciação) certos dilemas que antes se velavam sob a insuspeita designação de incapacidade técnica.

Palavras-chave: Cor; Atenção; Estética; Fotografia; Eggleston.

\section{To photographic colours and William Eggleston, brief reverence}

Abstract: This article will focus on the uproar that took place among critics of the photographic art over the installation of the colorful works of William Eggleston in 1976 at MoMA in New York. If the photographic colors were always desired as the Henisch couple claims, for example, substantiated by their extensive historical documentation, then why was Eggleston so vehemently ridiculed? From the heuristics of aesthetic attention theory, this work seeks to explain how Eggleston's act foregrounded certain dilemmas to our attention (and therefore, discussion and appreciation), dilemmas that were previously veiled under the unsuspect designation of technical incapacity.

Keywords: Colour; Attention; Aesthetics; Photography; Eggleston. 
1 Guia de William Eggleston, em tradução livre.

2 O jornal New York Times chamou a exposição de Eggleston de "o show mais detestado do ano". Cf. LACAYO (2008).

${ }^{3}$ No original: "put-on".

\section{Introdução}

Em 1976 William Eggleston chocou, atiçou e perturbou o mundo da arte ao ter seu trabalho, de fotografias coloridas, intitulado de William Eggleston Guide ${ }^{1}$, exibido no MoMA (Museu de Arte Moderna) em Nova lorque. Sua obra foi recebida com um chorrilho viperino tanto pela crítica especializada ${ }^{2}$ quanto por fotógrafos de renome - Ansel Adams "escreveu uma carta severa de protesto ao curador John Szarkowski, mal dizendo Eggleston, o chamando de embuste ${ }^{3 "}$ (CHILD, 2011: 38, tradução nossa). Dos críticos de arte renomados, por exemplo, Hilton Kramer "contrariou a afirmação do curador de que o show foi na verdade perfeito, escrevendo 'perfeitamente ruim, talvez... perfeitamente chato, com certeza' (GLOVER, 2013, tradução nossa). Mesmo em 2008, 32 anos após a exibição original no MoMA, a cor de Eggleston continuou sendo vociferada por críticos:

Os usos da cor em Eggleston insultam os valores intelectuais que foram, há muito, definidos pela fotografia moderna, incluindo os trabalhos de seus ídolos Cartier-Bresson e Evans. Meticulosas modulações tonais em preto-e-branco conduzem para a claridade mental e óptica; a cor confunde (SCHJELDAHL, 2008, tradução e grifo nosso).

A fala de Peter Schjeldahl aponta um dos caminhos mais frutíferos para a compreensão do ocorrido em 1976, da cor enquanto problema/tema/dilema central do trabalho de Eggleston. E da reação virulenta a sua adoção. Interessante notar, todavia, que a fotografia surgiu em 1839 , em preto-e-branco. A partir de sua invenção a fotografia foi considerada uma sensação tecnológica, adorada por todos. O que incomodava, que era pouco plausível, era a desconexão perceptiva com o mundo 'real': como uma mídia poderia ser capaz de 'capturar' tantos detalhes, com tamanha precisão, sem qualquer potencial de representar ou guardar as cores do mundo. Explicam os pesquisadores Heinz e Bridget Henisch:

As fotografias não eram somente 'cegas para as cores', no sentido de que as cores não eram gravadas ou apresentadas, mas essa mesma cegueira causava distorção em todas as escalas tonais no curso de sua tradução para o preto-ebranco, tornando todos os verdes e vermelhos muito escuros, e todos os azuis e violetas desproporcionalmente claros (1996: 1, tradução nossa).

Portanto, para além da imprecisão efetuada nas escalas gerais de cinza, havia um incômodo com a falta da cor. Ou seja, havia um desejo pela cor. Desejo esse que esbarrava na dificuldade tecnológica ${ }^{4}$ da implantação da cor na fotografia, avanço que só foi alcançado com sucesso em 1935 com a introdução no mercado do filme do tipo Kodachrome pela Eastman-Kodak:

Como bem sabia a Kodak, e os usuários do novo tipo de filme aprenderam rapidamente, o Kodachrome produzia a melhor resolução e duração do que qualquer outra película colorida que havia surgido antes - e praticamente desde então. Este fato permaneceu verdadeiro sobre o Kodachrome até 1990, quando a Fuji introduziu seu Process e-6 Fujichrome, o primeiro tipo de filme colorido que foi considerado de resolução mais nítida e granulação mais fina do que o Kodachrome (LURIE, 2015: 229, tradução nossa).

Antes da corrida tecnológica desembarcar no Kodachrome, porém, se faz necessário dar alguns passos para trás. A implantação da cor na fotografia era, de fato, tão ensejada que já em 1841, dois anos após sua invenção e 167 anos antes da ácida crítica de Peter Schjeldahl, foi inventada a primeira forma de colorir as fotografias. Colorir é a palavra que mais se adequa à técnica, posto que se tratava de pintura à mão. A técnica foi inventada por Henry Collen, em Londres. Collen era sócio do famosíssimo Fox Talbot, além de professor de pintura (ele deu aulas 
5 Cf. SOARES (2014). Mecanismos de colorização dos primeiros períodos do cinema: pintura à mão sobre película, estêncil, tintagem e viragem.

${ }^{6} \mathrm{O}$ mesmo problema atinge as películas cinematográficas. "A escolha de Martin Scorsese de realizar Touro Indomável em preto-e-branco foi fortemente influenciada por sua descoberta de que a cor das películas dos filmes que ele tinha dirigido há poucos anos já estavam desbotando" (MISEK, 2010: 112, tradução nossa).

7 Cf. MOURA (2001); JUSSAN (2005); HIRSCH (2011); ALTON (1995). para a Rainha Vitória). A prática se tornou corriqueira e ganhou a nobreza de Londres, inclusive a própria Rainha Vitória que "deu apoio à prática de colorização pelo ato simples, porém muito influente, de incluir fotografias pintadas à mão em sua coleção pessoal" (HENISCH, 1996: 13, tradução nossa). Da cor pintada ao Kodachrome foram 94 anos de tentativas de tipos de filmes de maior ou menor sucesso. $\mathrm{O}$ anseio pela cor pode ser conferido também na história do cinema, em quase exato déjà-vu aos percalços da fotografia ${ }^{5}$. Em sua tese de doutorado, defendida em 2007, o professor Joshua Yumibe comenta que a pintura à mão do cinema (das obras feitas na década de 1900) se tornou consideravelmente mais complexa e laboriosa conforme as durações dos filmes foram crescendo. $E$ também exponencialmente mais caras, pois cada cópia distribuída tinha que ser pintada individualmente. Então, o Yumibe indaga por que "tanto esforço foi empregado na colorização desses primeiros filmes? [...] Porque eles eram hits sensacionais com o público, e sendo assim, commodities prestigiosos [...]" (2007: 136, tradução nossa).

$\mathrm{O}$ anseio pela cor não poderia vir destituído da repulsa, no entanto. A frase do tradutor para o inglês de Jean-François Lyotard, Geoffrey Bennington, não deixa dúvidas da natureza desse jogo: "Nós devemos ter as cores, e cores repetidas, e múltiplas, para poder reclamar de sua vaidade, assim como Jeremias precisa de muitas palavras para dizer que elas não têm nada a dizer" (1993: 218, tradução nossa). Especificamente, a rejeição das cores se deu/dá em face de duas acusações principais: a primeira trata de seu suposto sequestro pelo comercialismo, como evidenciado pelas palavras escolhidas por Yumibe 'hit' e 'commodity'. "De acordo com (Tom) Gunning, a cor [...] (teve papel definidor) na formação de uma 'cultura do sensacionalismo baseada em intensidades sensuais e emocionais'” (HANSSEN, 2006: 73, tradução nossa). Essa crença faz surdir certos livros nas prateleiras, como o Psicodinâmica das Cores em Comunicação, que prometem que o estudo da cor "permite conhecer sua potência psíquica (para) aplicá-la como poderoso fator de atração e sedução [...]" (FARINA et al, 2006: 2, grifo nosso). A segunda acusação trata do fato de que as dificuldades tecnológicas para a implantação da cor nos filmes, já sanadas, não diminuem ou contornam as dificuldades técnicas e artísticas sobre a cor, após sua aplicação nas obras. Por exemplo, em relação à durabilidade ${ }^{6}$ das mesmas:

Todos os métodos de impressão de cor são fugazes, ou seja, eles desvanecem com o tempo. O maior inimigo é a descoloração pela luz, que é causada por todos os tipos de luzes ambientes e radiações ultravioletas. [...] O segundo adversário é descoloração escura, que começa assim que a imagem fica pronta. Causada pela humidade relativa do ambiente e pela temperatura, ela ocorre mesmo se a imagem for trancada numa caixa à prova de luz. Ambos os processos afetam os diversos materiais que compõem a imagem - embora não na mesma velocidade - causando alterações de cor com o tempo (HIRSCH, 2011: 306, tradução nossa).

Portanto, não há garantia de que todo o cuidadoso e extenuante ${ }^{7}$ trabalho de cor dos fotógrafos e cineastas será apreciado, sem retoques ou modificações, pelas gerações futuras. O próprio curador da mostra de Eggleston, John Szarkowski comenta sobre a questão artística:

Os gênios técnicos que desenvolveram este maravilhoso avanço presumiram, naturalmente, que mais é melhor, e que seria natural a junção das imagens antigas com a cor. [...] Para o fotógrafo que demanda rigor formal de suas imagens, a cor representava uma enorme complicação para um problema que já era cruelmente árduo. Analisando a falta de entusiasmo e confiança com a qual a maior parte dos fotógrafos ambiciosos tem considerado a cor, não é de se estranhar que a maioria do trabalho no meio tenha sido pueril. [...] Os mais interessantes destes podem ser descritos como fotografias em preto-e-branco 
feitas com película de cor, em que o problema da cor é resolvido por desatenção (1976: 8, tradução e grifo nosso).

David Batchelor (2014: 16-7), artista plástico e pesquisador inglês, defende a tese de que a mera presença da cor é incapaz de sustentar, por si, uma expressão artística. Ao contrário, a cor só se torna expressiva de alguma intenção do artista quando é tratada como 'substantivo' e não 'adjetivo', durante a criação. E foi exatamente $o$ ato de chamar a atenção para cor que se constituiu como danação ou salvação de Eggleston, a depender do ponto de vista entre seus detratores e defensores, os últimos surgidos a posteriori. Por exemplo, a matéria (intitulada Genius in colour, gênio em cores) veiculada no importante jornal The Independent, em 2013, deixa claro já no subtítulo que Eggleston é o "padrinho" da fotografia colorida, que ele inspirou uma geração entre David Lynch e Juergen Tellen, que ele foi honrado com um prêmio do Sony World Photography Awards e, por fim, que Eggleston terá uma exibição permanente no prestigioso museu Tate Modern de Londres (GLOVER, 2013, tradução nossa). Todas benesses colhidas pelo ato intencional e atencional, profundamente artístico, de adicionar cor e também expressividade à cor.

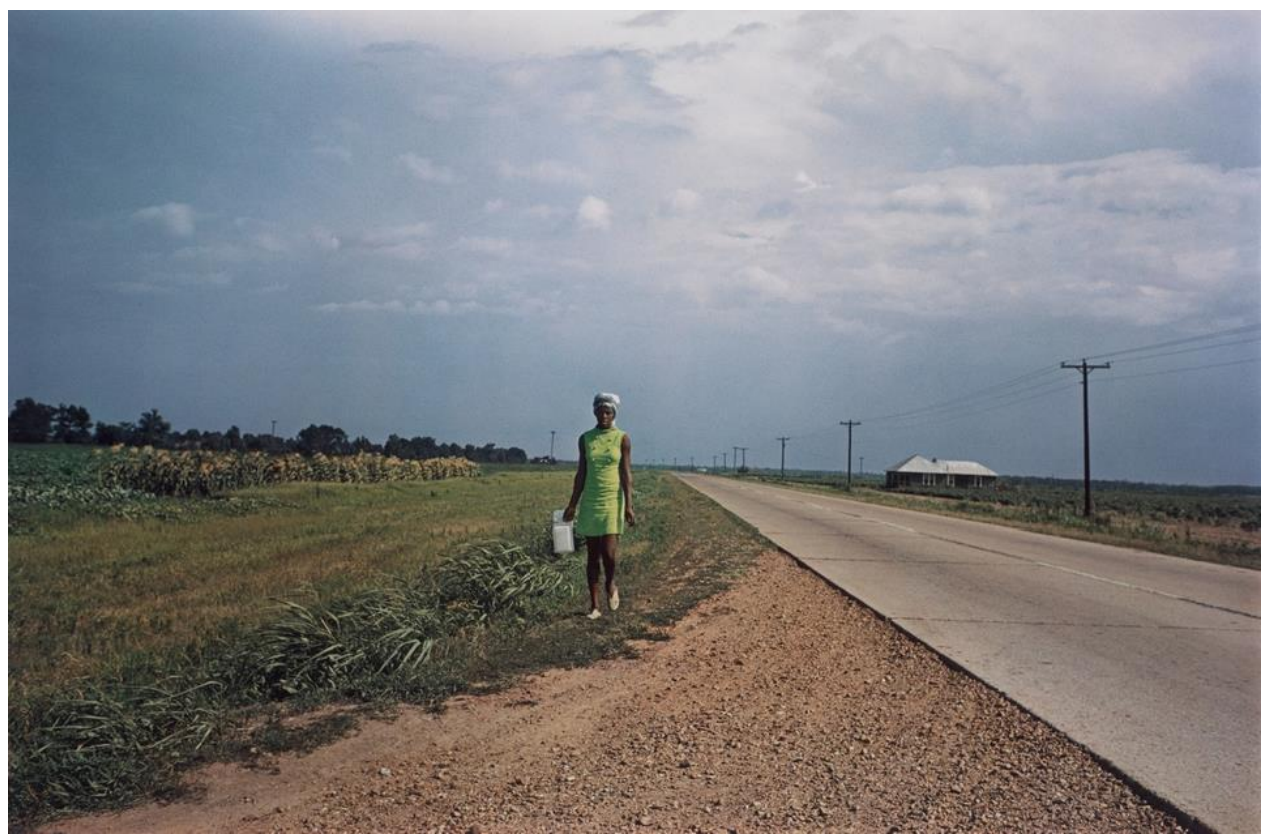

Figura 01. William Eggleston, Sem título (Perto de Minter City e Glendora, Mississippi), 1970.

\section{Atenção Estética, Apropriabilidade e Intenção}

Como seria possível fotografar todas as cores do mundo sem vê-las? Como alertou Szarkowski, de forma desatenta? Como seria possível olhar através delas, sem notar seu grito, sua presença incomensurável nas coisas, na luz, nos olhos? Gérard Genette elucida tal possibilidade com o conceito de "atenção aspectual". Explica o crítico literário francês que dentre os tipos possíveis de atenção, a aspectual é aquela marcada pela "percepção sem identificação prática" (1999: 7, tradução nossa). Para ilustrar o conceito, Genette traz uma história do pintor Gustave Coubert.

Conta-se que um dia, de repente, ocorreu a Coubert, enquanto ele estava trabalhando numa paisagem, que ele estava pintando por algum tempo um objeto distante sem saber do se tratava. Ele enviou um assistente para ir descobrir. O assistente voltou e disse, "Você está pintando uma pilha de lenha." Coubert estava, então, pintando um objeto "não identificado"; mas ele não ficou demasiado incomodado pelo fato, pois, como um pintor, seu interesse não era a identidade do objeto ("o que é isto?") - menos ainda sua 
função ("qual a finalidade disto?") - mas sim a aparência externa, seu aspecto, seus contornos e cores: "com o que isto se parece?" (GENETTE, 1999: 6)

${ }^{8} \mathrm{O}$ artista Sérgio Prata dá cursos e vende livros sobre o desenho detalhado da anatomia humana. Disponível em: http://goo.gl/brlv2r

Acesso em 01.03.16.

\footnotetext{
${ }^{9}$ A Mills \& Boon é uma centenária editora inglesa de romances populares que gozam de pouco prestígio crítico. De acordo com notícia veiculada no jornal The Observer, em 2008. Disponível em: http://goo.gl/AZAa7l

Acesso em 02.03.15.
}

A atenção aspectual do pintor estará focada nos aspectos relativos à pintura, como cores, luzes, formas, perspectiva, etc. A atenção aspectual de um músico, por exemplo, focaria em timbres, em arpejos, em dissonâncias, etc. Já a de um fotógrafo acostumado com o preto-e-branco, estará focada nos contrastes de luzes e sombras (claro-escuro), no enquadramento, na quantidade de total luz disponível e sua direção, etc. Em todos os elementos compositivos, menos na cor. Assim seria possível o 'olhar sem ver', pois o foco atencional do artista não contemplaria certos aspectos. Coubert estava tão concentrado na forma e na cor do objeto que não foi capaz de identifica-lo de forma pragmática. E, como ressalta Genette, tal fato - para a pintura - é irrelevante. O pintor não precisa saber para que serve, nem o que é, para pintar com excelência. Assim, pode pintar algo tão estranho e comum como os conjuntos de músculos esternocleidomastoídeos ${ }^{8}$ do pescoço humano, sem atentar para suas funções vitais ou pragmáticas dentro do corpo.

Pois, finalmente, a atenção do artista se converterá em intenção na obra acabada. Dito de outra forma, o artista imprime/exprime aquilo que foi objeto de sua atenção na feitura da obra, na obra. E exprime, através dos aspectos, toda a força de sua composição. A composição ou obra finalizada, por sua vez, afetará (ou não) o interesse/atenção dos receptores da obra, em profundidades diferentes.

Sugiro que o termo 'apropriabilidade' defina a congruência entre a resposta do leitor e a emoção expressa na obra. Anna Karenina e os romances da Mills \& Boon ${ }^{9}$ expressam a piedade; A Epopeia de Mr. Skullion expressa um humor tempestuoso. O leitor sensível é aquele que sabe qual emoção é expressa na obra e, então, é capaz de responder de forma congruente a ela; o leitor refinado é aquele que responde de forma congruente para obras que possuam um determinado tipo de mérito (CURRIE, 2008: 213-4, tradução nossa).

Antes de continuar a discussão sobre a atenção estética, no entanto, se faz necessário esclarecer outro ponto: o da recepção. A atenção aspectual, como Genette repete incessantemente em seu texto, não é estética por si - pois falta, ainda, a apreciação que pode ou não ocorrer. Ela é condição, portanto, primeiro passo de um movimento mais profundo. Recentes estudos advindos da área da psicologia são de grande auxílio para a compreensão da lógica que rege da atenção até a emoção estética.

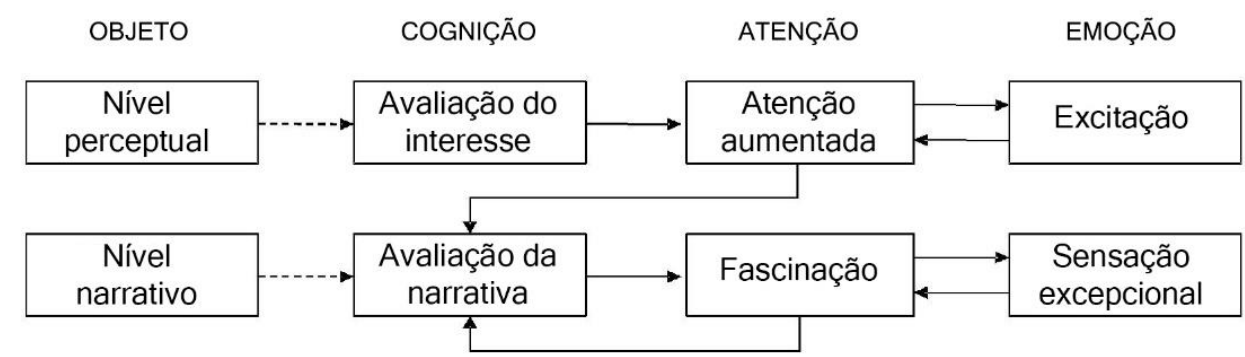

Quadro 01. Os estágios da atenção e da emoção estética ${ }^{10}$.

O professor de psicologia sérvio, Slobodan Marković, idealizador do quadro 01, confirma as teses de Genette, ao comprovar experimentalmente que o interesse por determinado aspecto, seja ele qual for (cor, forma, som, etc.), amplifica a atenção no observador. Uma vez em estado de profunda atenção, o aspecto é reavaliado. Uma vez que o interesse se confirme, a atenção cresce ainda mais, o que gera um estado de excitação. Quanto mais excitação, mais atenção. Pois 
11 Abordagens recentes para a Experiência Estética, em tradução livre. atenção e excitação se alimentam mútua e circularmente. Dessa forma, se passa para a segunda linha de retângulos, quando "outras avaliações se focam na detecção de regularidades de composição mais complexas e na interpretação das narrativas mais sofisticadas, além dos simbolismos ocultos na estrutura do objeto" (MARKOVIĆ, 2012: 6, tradução nossa). Ao final, surge a fascinação e uma 'sensação excepcional', uma emoção - que pode estar ligada ao prazer ou desprazer. A palavra-chave, aqui, é avaliação ou apreciação. $O$ sujeito tem sua atenção roubada por algum aspecto da obra e ele avalia se aquilo, de fato, o interessa ou não. Esta é a razão que leva Genette a comentar sobre o fato de que a atenção aspectual não é, necessariamente, estética por si. A atenção pode ser chamada de estética, propriamente, quando essa avaliação (ou apreciação) se materializa.

É Nöel Carroll quem oferece um ponto de contato entre Marković, Currie e Genette. Em texto de 2012, intitulado "Recent Approaches to Aesthetic Experience"11, Carroll afirma que as "obras de arte têm objetivos ou propósitos [...]. A forma da obra e as qualidades nela investidas são os meios pelos quais os propósitos da obra se concretizam. Dessa maneira, as experiências estéticas envolvem foco no modo de fazer da obra" (174, tradução nossa). Num exemplo concreto, importante tela de Pablo Picasso, abaixo, é possível delinear alguns elementos de intenção e apropriabilidade, manifestos na própria tessitura dos elementos compositivos elencados pelo autor/criador.

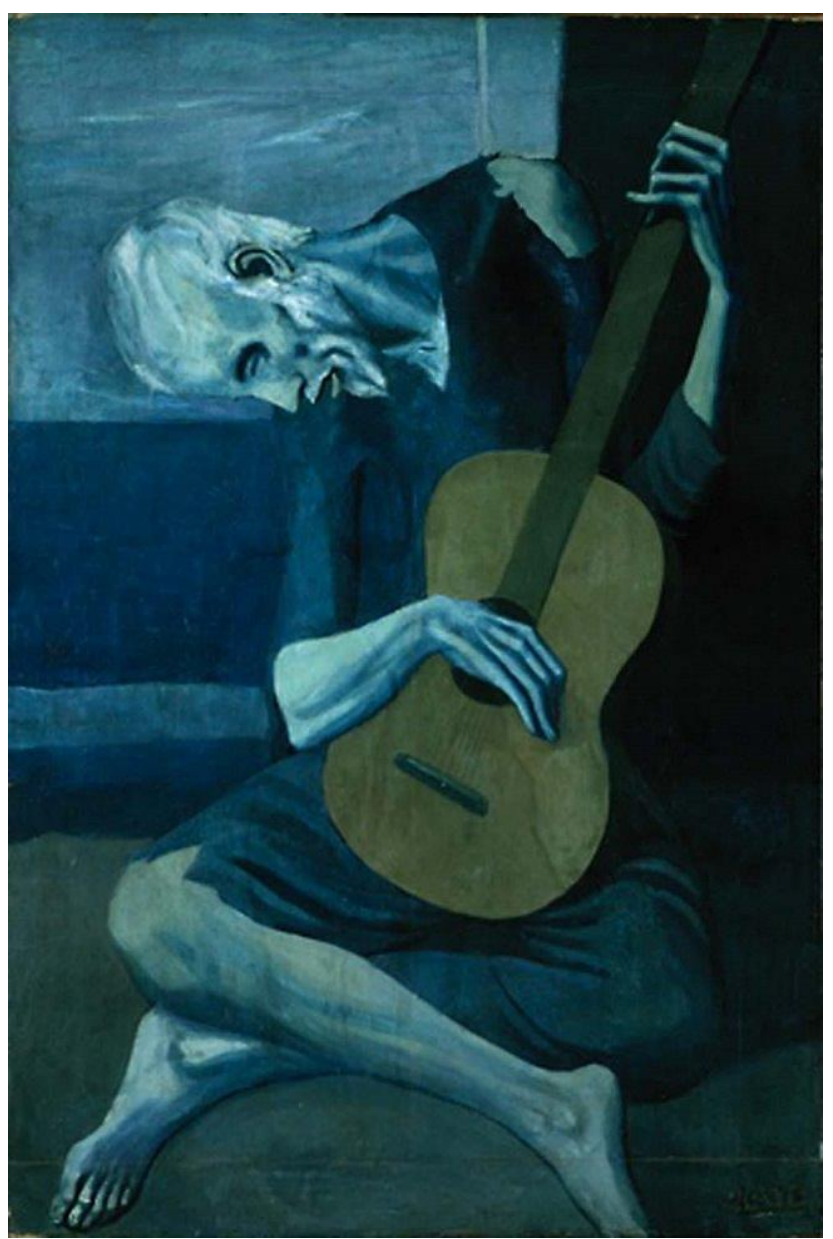

Figura 02. Pablo Picasso, Velho guitarrista cego, 1903.

A apropriabilidade de Gregory Currie aponta para a congruência da resposta do observador ao desígnio do autor/criador. Pois, em o Velho guitarrista cego há uma soma de elementos que expressam uma ideia ou conceito de tristeza. Para além da evidente posição corporal do homem representado, cabisbaixa; as linhas sofridas do rosto; as mãos deformadas; aqui, o aspecto central a ser analisado é 
12 Para os semioticistas, o nível legisigno. Tal nível, daquilo que seria compartilhado por uma ou várias culturas inteiras, esbarra justamente no próprio conceito de cultura. A leitura de uma obra ativa diversas competências diferentes, para além das emocionais inatas. A cultura na qual o sujeito está inserido tem papel fundamental para suas chaves interpretativas. A noção de cultura, no entanto, está em constante disputa. Cf. EAGLETON (2005), cap 2. Uma das definições possíveis: "Stuart Hall oferece uma igualmente generosa ideia de cultura como 'práticas vitais' ou 'ideologias práticas que permitem a uma sociedade, a um grupo ou a uma classe, experimentar, definir, interpretar e entender as suas condições de existência'"' (52).

${ }^{13}$ De acordo com o sítio oficial do pintor. Disponível em:

http://www.pablopicasso.org/old-

guitarist.jsp

Acesso em 03.03.15.
${ }^{14}$ Este trabalho não pretende resolver nenhuma questão de forma definitiva. Ao contrário, tem como objetivo apresentar e refinar hipóteses. "O Conhecimento constitui uma questão, não um problema. Problemas são passíveis de - e sempre clamam por - uma solução, já as questões se desdobram sempre, apresentando a cada novo movimento novos aspectos, e podendo, legitimamente, ser abordadas por mais de um viés" (AZAMBUJA, 2013: 597).

15 Entre o lançamento do daguerreotipo, em 1839 e o Kodachrome, em 1935. a cor. Wassily Kandinsky, artista plástico russo e importante nome da Bauhaus, define: "O azul profundo atrai o homem para o infinito, desperta nele o desejo de pureza e uma sede de sobrenatural" (KANDINSKY, 1996: 92). Demais, quando o azul está associado ao preto - ou a tons gerais escuros, como a parca luminosidade do quadro, por exemplo, ele "tinge-se de uma tristeza que ultrapassa o humano, semelhante àquela em que mergulhamos em certos estados graves que não têm nem podem ter fim" (ibidem: 93). Tal descrição dos efeitos do azul está em anuência com a atribuição geral ${ }^{12}$ dada ao azul, que caracteriza a cor como representante da "passividade, frigidez e obscuridade" (PEDROSA, 2009: 123). Segue abaixo um breve relato sobre a história da feitura do quadro:

O Velho guitarrista cego foi pintado em 1903, logo após o suicídio do amigo íntimo de Picasso, (Carlos) Casagemas. Durante este tempo, o artista demonstrou simpatia ao sofrimento dos oprimidos e pintou muitas telas que retratam as misérias dos pobres, os doentes e aqueles rejeitados pela sociedade. Picasso também sabia sobre o que era ser pobre, tendo vivido quase sem qualquer dinheiro durante todo o ano de $1902^{13}$.

Logo, se representar a tristeza era mesmo o mote de Picasso, ele o fez (para a cultura na qual estava inserido) de forma apropriada, posto que a apropriabilidade funciona tanto entre o receptor e a obra (do entendimento, em Currie) quanto entre o autor e a obra, onde se encontra a capacidade do artista de transmitir aquilo que ele deseja dizer/expressar. E tal capacidade é abundantemente variável: "Assim, os juízos estéticos podem vir em graus, com base na sofisticação da forma da obra - alguns trabalhos podem ser bons, mas outros podem ser ainda melhores" (CARROL, 2012: 175, tradução nossa). Em suma, a equação completa poderia ser assim descrita, de forma simplificada: os aspectos trabalhados na obra são compostos pela intenção do autor através de sua memória, afeto, sensibilidade e atenção às coisas do mundo, com certo filtro advindo de sua cultura; a obra pode ser bem resolvida ou não - apropriada para a transmissão de certa mensagem, fato a ser apreciado por cada indivíduo, sendo que tal julgamento só ocorre após a captura de sua atenção; cada indivíduo julga a obra a partir de seu próprio interesse - dada pelo grau de sua atenção - e também das ativações de sua memória, afeto, sensibilidade e filtro cultural (aqui, surgem ou não os cânones, positivos ou negativos).

\section{Duas hipóteses ${ }^{14}$ possíveis para o 'dilema' da cor em Eggleston}

Ao conclamar os olhos dos sujeitos para as cores, Eggleston igualmente conjurou os passos seguintes da atenção estética: apreciação e emoção. $O$ último passo, nesse caso, parece ter se concentrado no campo do desprazer, das emoções negativas. Por quê? Pistas para apurar esse dilema se encontram no texto de Ben Child.

[...] Eggleston diz de suas fotos. "Naturalmente, o conteúdo está ali. Elas são imagens deste lugar" (o Sul dos EUA). Então, suas fotos são da ordem de uma desconstrução. Elas usam características formais como a cor e a forma para revelar algo novo sobre o óbvio ele mesmo - um ato corajoso de desfamiliarização do que é ao mesmo tempo surpreendente e familiar (2011: 40, tradução nossa).

Familiar é a fotografia. Em preto-e-branco, que fique claro. O que é surpreendente é a cor. $\mathrm{E}$ é surpreendente pois foge daquilo que era esperado. $\mathrm{E}$ foge daquilo que era esperado uma vez que por $96 \operatorname{anos}^{15}$, ao menos, quem regeu a fotografia foi o preto-e-branco. Noventa e seis anos de formação e estabilização de técnicas, gênios e cânones. 
Fotógrafos talentosos, aprendendo com os sucessos de seus antecessores, rapidamente adquirem a capacidade de reconhecer e antecipar certos aspectos, como temas, situações, perspectivas e qualidade da luz que podem produzir imagens eficazes. Fotógrafos de cunho original ampliam esse sentimento comum de possibilidades ao descobrirem novos padrões que servirão como metáforas para suas intenções. Os insights contínuos e cumulativos destes artistas excepcionais têm formado e reformado a tradição da fotografia: um novo vocabulário pictórico, com base no específico, no fragmentário, no elíptico, no efêmero e no provisório. Esta nova tradição revisou nosso senso daquilo que no mundo é significativo e nossa compreensão de como o significativo pode ser descrito (SZARKOWSKI, 1976: 78, tradução nossa).

16 Frase dita em entrevista a Sérgio Groisman. Disponível em: http:/goo.gl/R9XmJw Acesso em 21.06.15
O 'significativo' era descrito, até 1976, majoritariamente em preto-e-branco. A chegada da cor estabeleceu uma lenta dirupção do 'vocabulário pictórico' descolorido. Afinal, a "transição da mídia para a cor [...] (permanece) numa incompletude perpétua" (MISEK, 2010: 84, tradução nossa). Entretanto, aponta Richard Misek, há um momento histórico singular a ser destacado. "No ano de 1965, houve um movimento de transição em bloco dos noticiários televisivos dos EUA para a cor" (id.). Dessa forma, Misek sustenta a tese que a partir daquele ponto determinado a noção de atualidade passou a ser transmitida/entendida/compartilhada em cores. Assim, em 1976, já vigoraria uma dualidade entre o 'aqui, atual ou corrente' (cor) e o 'outro lugar ou tempo' (preto-e-branco). No mundo da fotografia, entretanto, havia (e até hoje há, veja figura 03 abaixo) uma resistência que invertia esses valores, a saber: aqui e agora, atualidade era em preto-e-branco; cor representava o outro, tempo e/ou lugar. Esta é a primeira hipótese: a cor ainda é tratada como um elemento extra, novo, que não faz parte do 'aqui e agora', sim de 'outro lugar'. Que não estava lá quando Walker Evans, Eugène Atget ou Ansel Adams, etc., estabeleceram o cânone da 'fotografia de arte'. Por isso Sebastião Salgado diz que a cor é, para ele, uma "fonte de desconcentração profunda" ${ }^{16}$. Pois ela o desconcentra do mundo, da retidão do mundo. A cor obstrui o "esforço para perceber simplesmente o brilho cruel do que é" (AGEE apud RANKIN, 2011: 23, tradução nossa).

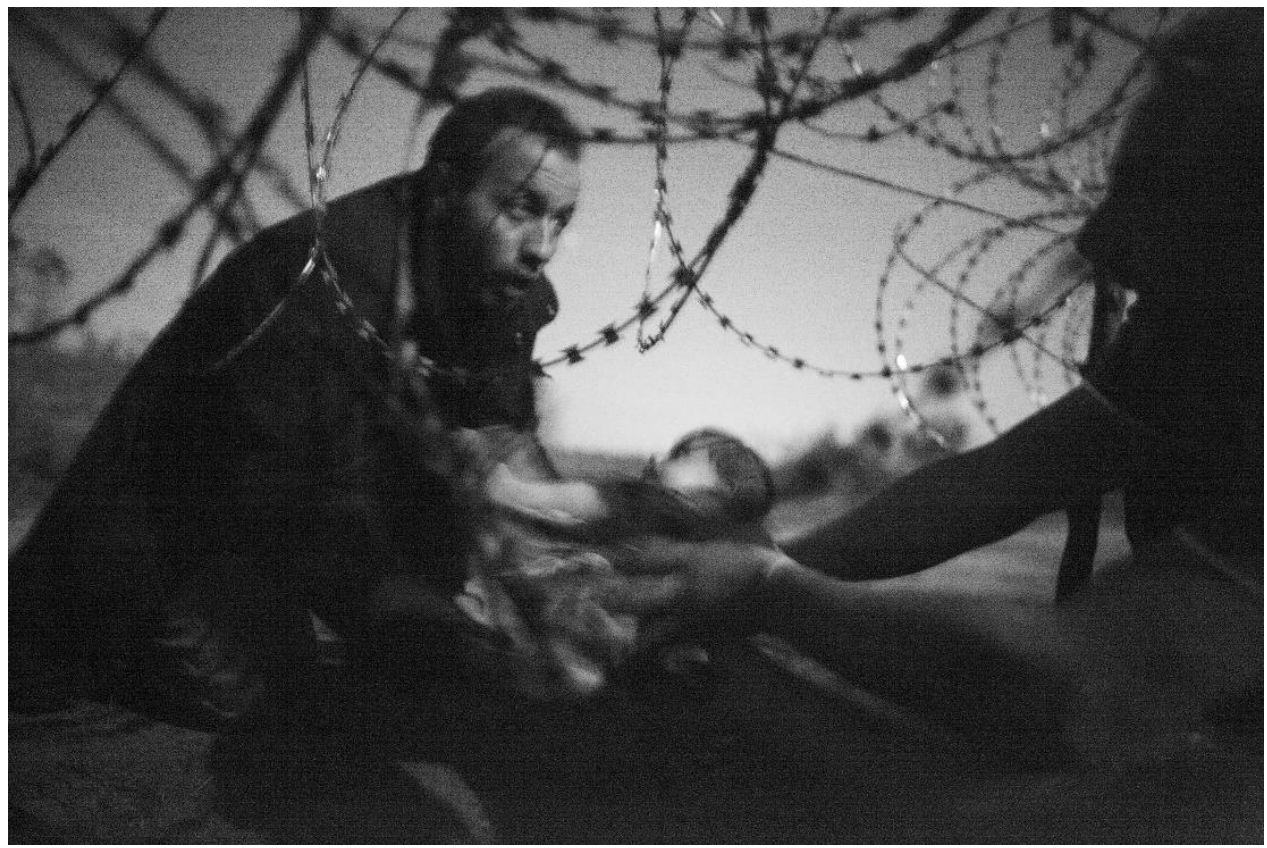

Figura 03. Warren Richardson, Esperança de uma nova vida, 2015.

A cor "tem um status de irrealidade; sua arbitrariedade consiste em sua desconexão com qualquer coisa; ela é uma adição ou suplemento; é artificial; ela adorna" (BATCHELOR, 2000:15, tradução nossa). A figura 03 foi a vencedora do prestigioso prêmio World Press Photo, edição de 2015. Ela trata de refugiados 
${ }^{17}$ De acordo com notícia veiculada no G1. Disponível em:

http://goo.gl/o1eUDI

Acesso em 20.02.16.
18 A película aerochrome foi desenhada para missões de reconhecimento aéreo. Ela é sensível à luz infravermelha. $\mathrm{Na}$ aplicação de Mosse, tudo aquilo que deveria ser figurado verde aparece com a cor rosa. Outras informações disponíveis em:

http://goo.gl/aePbHj

Acesso em 20.03.2015. que tentavam entrar na Hungria em agosto de 2015, e foi considerada "poderosa por sua simplicidade" pelo presidente do júri, Francis Kohn ${ }^{17}$. De acordo com o dicionário Houaiss da língua portuguesa, adornar (suposta função da cor) significa: i) colocar(-se) adornos ou enfeites; ornar(-se), ataviar(-se), enfeitar(-se); ii) por extensão de sentido: tornar (algo) atraente, agradável, interessante; embelezar, enriquecer com (conhecimentos, qualidades etc.). Logo, adornar é a antítese de simplificar (função do preto-e-branco). A segunda hipótese, que funciona em correlação com a primeira, lida com o fato de que aquilo que está adornado não pode fazer resplandecer o "brilho cruel do que é", posto que os adornos chamam a atenção para si e nos distraem. Nos tiram o foco do que é essencial, da dor do mundo. Da dor que acontece aqui e agora.

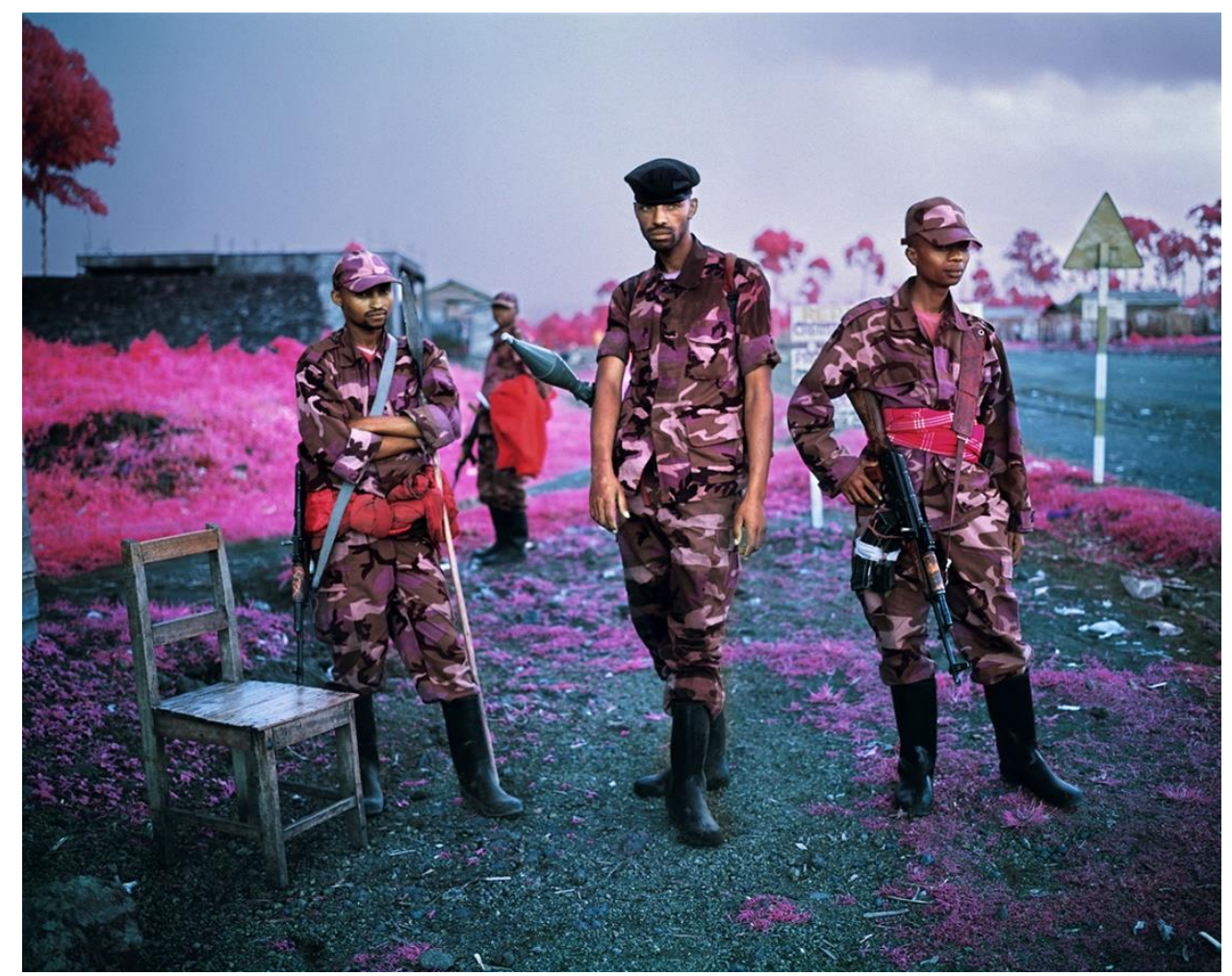

Figura 04. Richard Mosse, imagem da série Infra, 2012.

Tal acusação da cor como adorno, como elemento distrativo, é recorrente. A pesquisadora Jennifer Bajorek (2015: 230-1) analisou o trabalho do fotógrafo irlandês Richard Mosse, exemplificado na figura 04. As imagens tematizam a guerra na província de Nord-Kivu, na República Democrática do Congo. Mosse fez suas imagens com uma película especial da Kodak, a Aerochrome, cujo invento se deu para funções militares ${ }^{18}$ durante a Guerra do Vietnã. Bajorek explica que a cor rosa foi amplamente criticada, dada sua 'não seriedade' e alto grau de sedução - na direção de uma certa 'doçura', de uma alegria visual que não está, nem pode estar presente na dor da guerra.

Os críticos da arte fotográfica parecem insistir, então, no fato de que a fotografia em preto-e-branco seria possuidora de maior apropriabilidade para transcrever as dores do mundo para as imagens.

Aqueles ainda empenhados em definir a fotografia como uma arte sempre tentam persistir numa linha de argumentação. Mas é impossível persistir na mesma linha: toda tentativa de restringir a fotografia a certos temas ou certas técnicas, por mais frutífera que se revele, está condenada a ser contestada e a sucumbir. Pois é da própria natureza da fotografia ser uma forma de ver promíscua e, em mãos talentosas, um meio de criação infalível (SONTAG, 2004: 237). 
A reflexão de Susan Sontag se solidariza com o pensamento do próprio Eggleston: "Eu estou em guerra com o óbvio" (apud RANKIN, 2011: 4, tradução nossa).

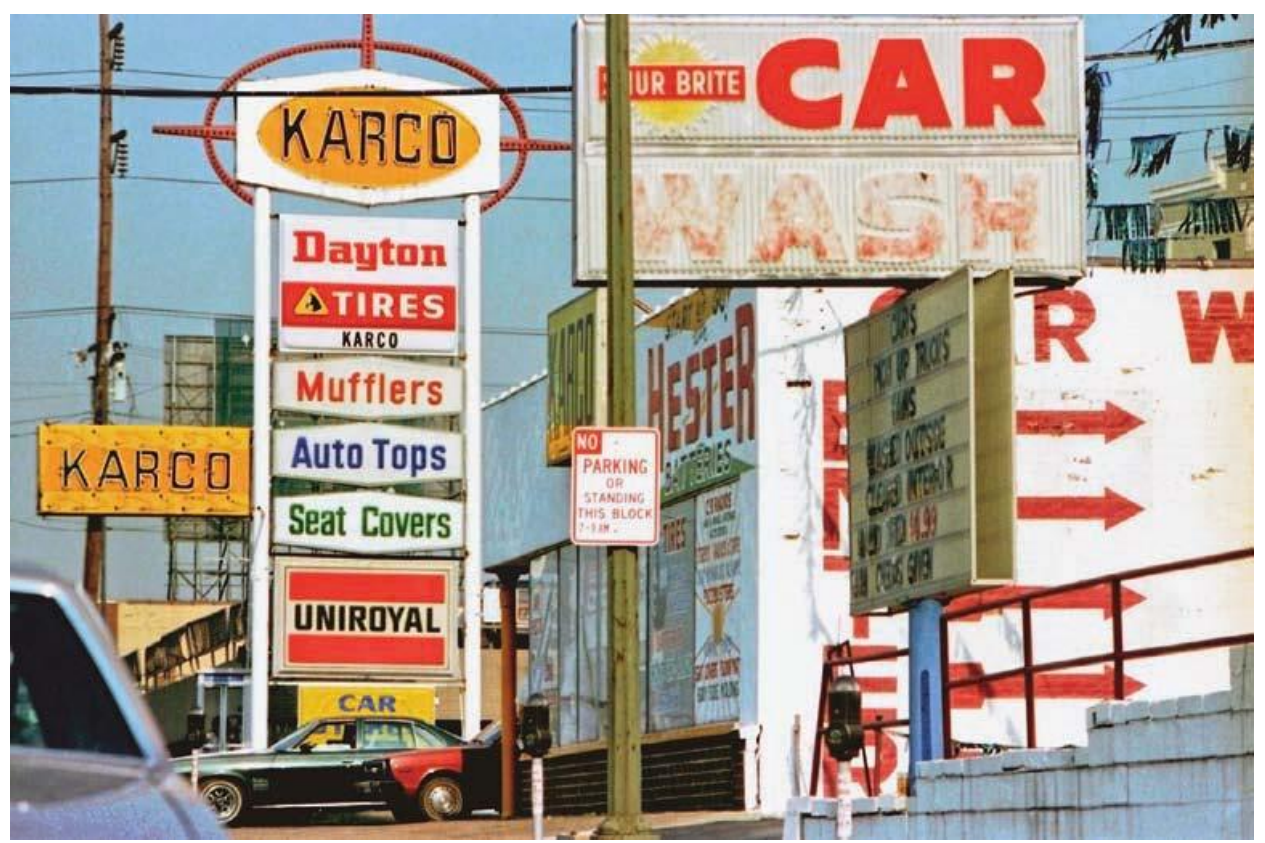

Figura 05. William Eggleston, Karco, c. 1983-86.

\section{Referências}

ALTON, J. Painting with Light. Berkeley: University of California Press, 1995.

AZAMBUJA, C. R. Sensação, percepção e entendimento: Peirce e a Teoria do Conhecimento. In: IV ENCONTRO NACIONAL DE ESTUDOS DA IMAGEM. 7 a 10 de maio/2013. Anais eletrônicos... Disponível em <http://goo.gl/ZOYSNd>. Acesso em 10.10.14.

BAJOREK, J. On Colour Photography in an Extra-Moral Sense. Third Text, vol.29 no.3, 2015, pp.221-235. Disponível em <http://goo.gl/nxbfE3>. Acesso em 15.12.15.

BATCHELOR, D. Chromophobia. Londres: Reaktion, 2000. . The Luminous and the Grey. Londres: Reaktion, 2014.

BENNINGTON, G. Epilogue. In: LYOTARD, J. Sam Francis, lessons of darkness. Lovaina: Leuven University Press, 1993.

CARROLL, N. Recent Approaches to Aesthetic Experience. The Journal of Aesthetics and Art Criticism, vol.70 no.2, mar-jun 2012. Disponível em <http://goo.gl/hcNeJg>. Acesso em 05.12.15.

CHILD, B. Mapping The Democratic Forest: The Postsouthern Spaces of William Eggleston. Southern Cultures, v. 17, n. 2., jun-set 2011. Disponível em $<$ https://goo.gl/X7mzTx>. Acesso em 09.09.15.

CURRIE, G. The Nature of Fiction. Nova lorque: Cambridge University Press, 2008 EAGLETON, T. A Ideia de Cultura. São Paulo: Unespe, 2005.

FARINA, M.; PEREZ, C.; BASTOS, D. Psicodinâmica das Cores em Comunicação. São Paulo: Blucher, 2006.

GENETTE, G. The Aesthetic Relation. Ithaca: Cornell University Press, 1999. 
GLOVER, M. Genius in colour: Why William Eggleston is the world's greatest photographer. The Independent, Londres, 22.04.13. Disponível em <http://goo.gl/qM5o4b>. Acesso em 01.02.16.

HANSSEN, E. Early Discourses on Colour and Cinema - Origins, Functions, Meanings. Stockholm, 2006.

HENISCH, H. K.; HENISCH, B. A. The Painted Photograph 1839-1914. Pensilvânia: Pennsylvania State University Press, 1996.

HIRSCH, R. Exploring Color Photography. Nova lorque: Focal Press, 2011.

HOUAISS, A. Dicionário Eletrônico Houaiss da língua portuguesa. Rio de Janeiro: Editora Objetiva, 2009. Versão 3.0. CD-ROM.

JUSSAN, C. Design Cinematográfico: A concepção visual do imaginário fantástico. Dissertação de Mestrado, UFMG, 2005. Disponível em <http://goo.gl/uAzZam>. Acesso em 07.07.14.

KANDINSKY, W. Do Espiritual na Arte - e na pintura em particular. São Paulo: Martins Fontes, 1996.

LACAYO, R. Light Fantastic, William Eggleston didn't just make color respectable. He made banality seem, well, colorful. TIME, Nova lorque, 31.10.08. Disponível em <http://goo.gl/t9veeU>. Acesso em 07.02.16.

LURIE, P. Faulkner 's Literary Historiography: Color, Photography, and the Accessible Past. Philological Quarterly, 90, no. 2\&3, 2011, pp. 229-253. Disponível em <http://goo.gl/WckFDa>. Acesso em 01.02.15.

MARKOVIĆ, S. Components of aesthetic experience: aesthetic fascination, aesthetic appraisal, and aesthetic emotion. i-Perception, v. 3, jan-2012. Disponível em <http://goo.gl/tCQTfC>. Acesso em 08.01.16.

MISEK, R. Chromatic Cinema - a history of screen color. Londres: Wiley-Blackwell, 2010

MOURA, E. 50 Anos Luz, Câmera e Ação. São Paulo: SENAC, 2001.

PEDROSA, I. Da cor à cor inexistente. Rio de Janeiro: SENAC, 2009.

RANKIN, T. The Cruel Radiance of the Obvious. Southern Cultures, v. 17, n. 2, junset-2011, pp. 3-23. Disponível em <http://goo.gl/8M397t>. Acesso em 09.09.15.

SCHJELDAHL, P. Local Color, William Eggleston at the Whitney. The New Yorker, Nova lorque, 17.11.08. Disponível em <http://goo.gl/2FKosi>. Acesso em 01.02.16.

SOARES, N. C. A cor no cinema silencioso do Brasil (1913-1931): produção e linguagem. Dissertação de Mestrado. ECA-USP, 2014. Disponível em <http://goo.gl/bz7UJN>. Acesso em 07.07.15.

SONTAG, S. Sobre fotografia. São Paulo: Companhia das Letras, 2004. Versão Kindle (epub).

SZARKOWSKI, J. William Eggleston's Guide. Nova York: The Museum of Modern Art, 1976.

YUMIBE, J. Moving Color: an aesthetic history of applied color technologies in silent cinema. Tese de Doutorado. Universidade de Chicago, 2007. Disponível em $<w w w$.proquest.com>. Acesso em 30.02.16. 